\title{
IPSS-R Risk Category
}

National Cancer Institute

\section{Source}

National Cancer Institute. IPSS-R Risk Category. NCI Thesaurus. Code C162679.

The risk category for myelodysplastic syndrome progression that is derived from IPSS-R risk score. 